\title{
Complementary Foods from Rice and Six Other Ghanaian Food Ingredients Provide Sufficient Macro and Micronutrients for Infants 6-12 Mo of Age
}

\author{
Ruth Adisetu Pobee ${ }^{1,2}$, Hannah Oduro-Obeng ${ }^{2}$, Paa-Nii Torgbor Johnson ${ }^{3,4}$, Paa Toah Akonor ${ }^{2}$ \\ ${ }^{1}$ Department of Nutritional Sciences, The Pennsylvania State University, University Park, Pennsylvania, USA \\ ${ }^{2}$ CSIR-Food Research Institute, Accra, Ghana \\ ${ }^{3}$ Department of Agroprocessing Technology and Food Biosciences, CSIR-College of Science and Technology, Accra, Ghana \\ ${ }^{4}$ P. N. J Partners Limited, Adabraka, Ghana
}

\section{Email address:}

rapobee@gmail.com (R. A. Pobee), hanoduro@yahoo.com (H. Oduro-Obeng), paanii.johnson@gmail.com (Paa-Nii T. J.), papatoah@gmail.com (P. T. Akonor)

\section{To cite this article:}

Ruth Adisetu Pobee, Hannah Oduro-Obeng, Paa-Nii Torgbor Johnson, Paa Toah Akonor. Complementary Foods from Rice and Six Other Ghanaian Food Ingredients Provide Sufficient Macro and Micronutrients for Infants 6-12 Mo of Age. Journal of Food and Nutrition Sciences. Vol. 5, No. 3, 2017, pp. 79-85. doi: 10.11648/j.jfns.20170503.14

Received: March 14, 2017; Accepted: March 30, 2017; Published: April 17, 2017

\begin{abstract}
Food base approach is considered to be a more viable and sustainable method of addressing micronutrient deficiencies in developing countries. A study to develop suitable micronutrient-rich complementary infant foods was carried out and characterized using rice (Oryza sativa, var. Togo Marshal) and six other Ghanaian food ingredients; soybean (Glycine Max var. Afayak), cowpea (Vigna unguiculata, var. Bengpla), mango (Magnefera indica, var. Kent), red palm (Elaesis guineensis. var. Dura) oil, groundnut (Arachis hypogea, var. Otuhia) and eggs. The complementary foods were initially developed from six blends, $L R-1$ ( $70 \%$ rice, $20 \%$ soybean, $5 \%$ groundnut, $5 \%$ dried mango), $L R-2(70 \%$ rice, $20 \%$ soybean, $5 \%$ groundnut, $5 \%$ egg yolk), $L R-3(70 \%$ rice, $20 \%$ soybean, $5 \%$ cowpea, $5 \%$ dried mango), $L R-4$ ( $65 \%$ rice, $25 \%$ soybean, $5 \%$ palm oil, $5 \%$ egg yolk), $L R-5$ (70\% rice, $20 \%$ cowpea, $5 \%$ groundnut, $5 \%$ egg yolk), $L R-6$ (70\% rice, $25 \%$ soybean, $5 \%$ dried mango). Sensory evaluation of these initial blends was conducted and the three most preferred blends were selected for further acceptability studies as well as the nutritional analyses using standard methods. The most desirable product based on sensory attributes was the formulation containing mango flour and soybeans (LR-6) followed by formulation containing soybean, groundnut and mango (LR-1). However there were no significant differences $(p=0.05)$ observed among the overall acceptability of the three best formulated products (LR-6, LR-1, LR-4). LR-4 had the highest amount of energy $(427.6 \mathrm{Kcal} / 100 \mathrm{~g})$, protein $(15.82 \mathrm{~g} / 100 \mathrm{~g})$, fat $(12.2 \mathrm{~g} / 100 \mathrm{~g})$, beta-carotene $(5106.7 \mu \mathrm{g} / 100 \mathrm{~g})$ and iron $(6.6 \mathrm{mg} / 100 \mathrm{~g})$. LR-6 came out as the most preferred weaning food based on sensory evaluation. This study revealed the potential of using local ingredients including rice to produce micronutrient-rich complementary infant foods in developing countries. This will be of tremendous help to the less endowed households where the problem of infant malnutrition is most rife.
\end{abstract}

Keywords: Infant Complementary Foods, Ghanaian Local Foods, Vitamin A, Iron, Micronutrient

\section{Introduction}

Micronutrient deficiencies remain a challenge around the world, especially in developing countries. Food base approach has been shown to be a more viable and sustainable method to address micronutrient deficiencies [1, 2, 3, 4] In many developing countries, the problem of nutrient deficiencies is partly due to the untap potential of local food [5]. Locally available food ingredients such as rice, soybean, cowpea, groundnuts, palm oil, mangoes and egg yolk are rich in specific micronutrients important for infant growth and development.

Rice commonly grown in Ghana is a very rich carbohydrate source with high proportions in bran, a rich source of antioxidants [6]. Soybean is high in protein and fat. 
Egg is rich in protein, amino-acid, iron and Vitamin A and while mango is rich in dietary fibre, Vitamin E, beta-carotene as well as essential minerals such as calcium, potassium and phosphorus $[7,8,9,10,11,12,13]$. Red palm oil is a rich source of beta-carotene which can subsequently be converted to vitamin A by the human body. It is also culturally acceptable and used in the preparation of various traditional foods. It is a rich source of antioxidants which acts as a buffer against free radicals. Food products with red palm oil such as biscuits have shown improvement in the vitamin A status after consumption [14]. These food ingredients when combined in right proportions in complementary foods may increase the nutrient contents of such infant foods and thus help solve the problem of micronutrient deficiencies commonly observed among infants. In most developing countries, these food ingredients are cultivated and used mainly in the preparation of traditional staple food by the rural dwellers. Their potential in diversified food product developments and alternative food preparations has not been fully exploited. Given their rich micronutrient sources, they are therefore good candidates for food base programmes aimed at addressing poor nutrition in infants in developing countries. This study therefore aimed at developing complementary foods from soybean, cowpea, groundnuts, palm oil, mango and egg yolk that can help solve the problem of micronutrient deficiencies in infant 6-12 mo of age in developing countries. We further determined the nutritional profile, sensory characteristics, and acceptability of the developed weaning food.

\section{Materials and Methods}

\subsection{Raw Materials}

The food ingredients used in this study were Rice (Oryzae sativa, var. Togo Marshall), soybean (Glycine max var. Afayak), cowpea (Vigna unguiculata, var. Bengpla) mango (Magnefera indica var. Kent), red palm (Elaesis guineensis var. Dura) oil, groundnut (Arachis hypogea var. Otuhia) and eggs. These were all obtained from an accredited supplier in Accra.

\subsection{Preparation of Rice, Soybean, Cowpea and Mango Flour Samples}

The rice sample was cleaned and sorted to remove chaff and other foreign materials, milled into flour using a hammer mill (Christy and Norris Ltd., Surrey, UK) and sieved to obtain a flour of uniform particle size $(250 \mu)$. For the soybean and cowpea flours, five hundred gram each raw material sample was blanched separately in $1 \mathrm{~L}$ of water for $30 \mathrm{~min}$ at $100^{\circ} \mathrm{C}$, after the initial cleaning and sorting, The legumes were then cooled at room temperature of $28^{\circ} \mathrm{C}$, spread thinly on stainless steel drying trays, and dried in a hot air oven at $60^{\circ} \mathrm{C}$ for $8 \mathrm{~h}$, dehulled in a disc attrition mill (Hunt No. 2A Premier Mill, Hunt \& Co., UK), winnowed and milled into flour of uniform particle size $(250 \mu)$ using the hammer mill. To obtain the mango flour sample, Kent mangoes, at Stage 4 ripeness with average $13^{\circ}$ Brix [15], were first washed under running tap water, peeled and sliced into very thin pieces for easy drying and dried at $60^{\circ} \mathrm{C}$ for $18 \mathrm{~h}$ in an oven. The dried mangoes were added to the rice, milled together and then sieved in a $250 \mu$ mesh for uniform particle sizes. Combinations that involved both mangoes and groundnuts in their desired quantities were added to the rice and all three ingredients were milled in the hammer mill before sieving to obtain a uniform particle size. The rice, soybean, cowpea and mango flours were all kept in airtight clear polypropylene bags in a refrigerator at $4^{\circ} \mathrm{C}$ until ready to use.

\subsection{Preparation and Incorporation of Groundnut Flour, Egg and Palm Oil Samples}

Prior to preparing the groundnut sample, care was taken to eliminate the possibility of mycotoxins using the CRSP procedure [16]. This involved sorting out the immature, shriveled, discolored and damaged kernels from the clean kernels and then roasting in an oven at $140^{\circ} \mathrm{C}$ for $30 \mathrm{~min}$ with intermittent stirring every $10 \mathrm{~min}$. The roasted groundnuts was mixed with the rice flour and milled together in the hammer mill (at inclusion levels indicated in Table 1) into flour. The flour was then sieved through a $250 \mu$ mesh to obtain a uniform particle size, packaged airtight in clear polypropylene bags and stored at in a refrigerator at $4{ }^{\circ} \mathrm{C}$. The egg yolk and palm oil samples were added into a small portion of flour through the rubbing-in method. A manual mixer was then used to thoroughly mix the desired quantity of flour to obtain a uniform combination. To obtain an extended shelf life, final flour combinations with egg and palm oil mix was slightly roasted under low temperature in the hot-air oven at $60^{\circ} \mathrm{C}$ for 20 minutes.

\subsection{Blend Formulation}

Different blend formulations (Table 1) used were based on the RDA of children below 5 years and the nutrient content of each ingredient [17].

Table 1. Composition of Complementary food formulations Used for the Study.

\begin{tabular}{|c|c|c|c|c|c|c|c|}
\hline \multirow{2}{*}{ Formula } & \multicolumn{7}{|c|}{ Component (\%) } \\
\hline & Rice flour & Soybean & Cowpea & G'nuts & Palm oil & Mango flour & Egg yolk \\
\hline LR1 & 70 & 20 & - & 5 & - & 5 & - \\
\hline LR2 & 70 & 20 & - & 5 & - & - & 5 \\
\hline LR3 & 70 & 20 & 5 & - & - & 5 & - \\
\hline LR4 & 65 & 25 & - & - & 5 & - & 5 \\
\hline LR5 & 70 & - & 20 & 5 & - & - & 5 \\
\hline LR6 & 70 & 25 & - & - & - & 5 & - \\
\hline
\end{tabular}

G'nuts: Groundnuts 


\subsection{Preparation of Porridge}

One hundred gram of each flour formula was mixed in 880 $\mathrm{ml}$ of water and stirred to obtain a slurry. A pinch of salt (less than $1 \mathrm{~g}$ ) and $20 \mathrm{~g}$ of sugar were added and the slurry boiled for 6-8 min. Porridge was served in $30 \mathrm{~mL}$ polypropylene tumblers while still lukewarm.

\subsection{Sensory Evaluation}

The sensory attributes of appearance, colour, aroma, taste, texture, mouth feel, aftertaste and overall acceptability of all six products were initially evaluated using a nine- point hedonic scale ranging from 1 (dislike extremely) to 9 (like extremely), by a panel comprising 10 mothers whose children were aged between 6 and 59 mo. These mothers were specially recruited and trained as expert panelists, after they had given their consent to take part in the study. Panelists were provided with an unsalted cracker and water to refresh their palate before evaluating successive samples.

These mothers were further used to refine the developed products to help select the best three complementary food formulae. The refining involved asking the mothers to rate their acceptability of the products and make comments and suggestions on what could be done to improve on product. For example, if almost all the mothers said a particular product was too beany, we went ahead to reduce the percentage of cowpea beans etc. Through this, the products were improved based on their comments and sent back to them for another re-evaluation. This was done about three times in order to get an improved product for each combination. They helped select the three best products that were used for the subsequent acceptability tests. All sensory evaluations were carried out in a facility conforming to ISO 8589 .

\subsection{Consumer Acceptability}

The three selected formulae (LR-1, LR-4 and LR-6) from the sensory evaluation were used for the consumer preference testing, which involved another set of sixty mothers, whose children aged between 6 and 59 mo, as panelists. These panelists were recruited from 5 child-care/weighing centers in the La Nkwantanan-Madina District, Accra. The mothers consented to be part of the study were after the whole study was fully explained to them. These mothers assessed the colour, appearance, taste, aroma, mouth feel, constituency and overall acceptability of porridge samples prepared from the 3 newly developed formulae, using the 9-point hedonic scale with 1 representing "dislike very much" and 9 representing "like very much.

\subsection{Nutritional Composition of Weaning Blends}

Proximate composition, mineral and vitamin A were determined for the best 3 complementary food formulae using standard procedures [18]. Carbohydrate was calculated by difference. Energy values were determined using Atwater factors $3.47,8.37$ and 4.00 for protein, fat and carbohydrates respectively [19].

\subsection{Statistical Analysis}

The sensory evaluation data was analyzed using a one-way analysis of variance (ANOVA) with the different formulations as the main factor. A $0.05 \%$ level of significance was adopted to establish differences between attributes of the different preparations. Significantly different means were separated using Duncan's Multiple Range Test (SPSS 17.0.1).

\section{Results}

\subsection{Trained Panel Sensory Evaluation for 6-Porridges Made from Complementary Food Formulae}

Table 2 presents the results of sensory assessment of porridge prepared from all 6 initial complementary formulations. Colour, aroma and taste of the blends showed significant differences. LR-1 was best in aroma and mouth feel, while LR-2 was best for consistency. LR-4 was best in appearance, although it was not significantly different $(\mathrm{p}>0.05)$ from the other formulations. LR- 6 was best in colour and taste and showed significant differences $(p<0.05)$ when compared with LR-2 and LR-4 in terms of colour. LR6 which contained mango was also significantly higher in taste compared with LR-2, LR-3 and LR-5. Scores for aroma varied widely and ranged between 2.3 and 8.2 . LR-5 and LR3 which contained cowpea was the least preferred in terms of aroma and taste.

Table 2. Sensory attributes of the six initial complementary food formulations.

\begin{tabular}{|c|c|c|c|c|c|c|}
\hline \multirow{2}{*}{ Sensory Attribute } & \multicolumn{6}{|c|}{ Formulation } \\
\hline & LR-1 & LR-2 & LR-3 & LR-4 & LR-5 & LR-6 \\
\hline Appearance & $8.0 \pm 1.0^{\mathrm{a}}$ & $7.8 \pm 1.2^{\mathrm{a}}$ & $7.6 \pm 0.8^{\mathrm{a}}$ & $8.5 \pm 0.3^{\mathrm{a}}$ & $7.8 \pm 0.8^{\mathrm{a}}$ & $7.8 \pm 1.0^{\mathrm{a}}$ \\
\hline Colour & $7.3 \pm 0.8^{\mathrm{ab}}$ & $5.1 \pm 1.1^{\mathrm{a}}$ & $5.2 \pm 0.9^{\mathrm{a}}$ & $8.6 \pm 0.4^{b}$ & $7.8 \pm 1.0^{\mathrm{b}}$ & $7.8 \pm 0.8^{\mathrm{b}}$ \\
\hline Aroma & $8.2 \pm 0.6^{\mathrm{b}}$ & $4.1 \pm 2.1^{\mathrm{a}}$ & $3.1 \pm 1.0^{\mathrm{a}}$ & $7.9 \pm 0.9^{\mathrm{b}}$ & $2.3 \pm 1.5^{\mathrm{a}}$ & $7.8 \pm 0.6^{\mathrm{b}}$ \\
\hline Taste & $7.8 \pm 0.9^{\mathrm{b}}$ & $5.3 \pm 0.8^{\mathrm{a}}$ & $4.2 \pm 1.1^{\mathrm{a}}$ & $7.8 \pm 0.6^{\mathrm{b}}$ & $3.3 \pm 1.4^{\mathrm{a}}$ & $8.0 \pm 0.6^{\mathrm{b}}$ \\
\hline Consistency & $7.1 \pm 1.2^{\mathrm{a}}$ & $7.8 \pm 1.4^{\mathrm{a}}$ & $6.4 \pm 1.0^{\mathrm{a}}$ & $7.4 \pm 1.2^{\mathrm{a}}$ & $6.3 \pm 1.1^{\mathrm{a}}$ & $7.1 \pm 0.8^{\mathrm{a}}$ \\
\hline Mouth-feel & $8.1 \pm 0.6^{\mathrm{a}}$ & $7.4 \pm 1.0^{\mathrm{a}}$ & $7.2 \pm 0.9^{\mathrm{a}}$ & $6.3 \pm 1.4^{\mathrm{a}}$ & $7.2 \pm 0.4^{\mathrm{a}}$ & $7.9 \pm 1.0^{\mathrm{a}}$ \\
\hline
\end{tabular}

Means in the same row with different superscripts are significantly different $(\mathrm{p}<0.05)$

Acceptability and limiting sensory factors for the initial six complementary food formulations are given in Table 3. Two out of three products, which had mango flour were liked "very much" and "extremely" and the remaining one, which 
contained cowpea, was moderately preferred by trained panelist. The addition of mango flour to the formulations with soybeans gave it an attractive colour. This therefore enhanced the overall acceptability of the formulations containing mango flour. LR-1, LR-4 and LR-6 had no limiting sensory attribute. LR-2 was limited in aroma while
LR-3 and LR-5 were limited in both taste and aroma. LR-6 was ranked as the most preferred, LR-1 and LR-4, very much preferred, LR-3 and LR-2 moderately preferred and LR-5 slightly preferred. The three most preferred products (LR-1, LR-4, LR-6), based on overall acceptability, were used for the final consumer acceptability testing.

Table 3. Acceptability and Limiting Sensory Factors of the six complementary food formulations.

\begin{tabular}{llll}
\hline Formula & Acceptability & Inference & Limiting Sensory attributes (s) \\
\hline LR-1 & $8.3 \pm 0.6^{\mathrm{b}}$ & Very much & None \\
LR-2 & $6.6 \pm 1.0^{\mathrm{a}}$ & Moderately & Aroma \\
LR-3 & $6.8 \pm 0.6^{\mathrm{a}}$ & Moderately & Taste and Aroma \\
LR-4 & $8.4 \pm 0.4^{\mathrm{b}}$ & Very much & None \\
LR-5 & $6.3 \pm 1.3^{\mathrm{a}}$ & Slightly & Taste and Aroma \\
LR-6 & $8.6 \pm 0.4^{\mathrm{b}}$ & Extremely & None \\
\hline
\end{tabular}

Means with different superscripts are significantly different $(\mathrm{p}<0.05)$

\subsection{Consumer Acceptability for the Three Preferred Complementary Food Formulations}

Figure 1 presents a pictorial summary of results from consumer acceptability studies on porridge prepared from the three most preferred formulae, namely LR-1, LR-4 and LR-6.

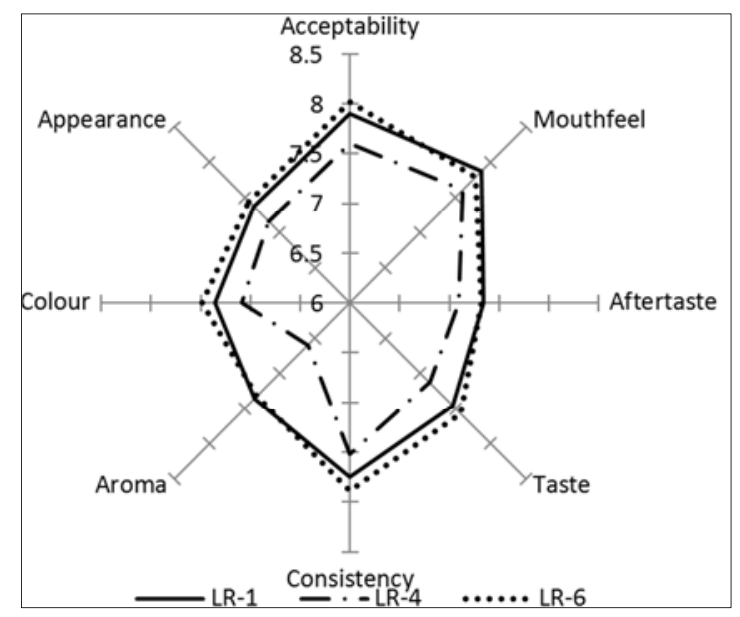

Figure 1. Profile of sensory attributes from consumer acceptability test of the three preferred complementary food formulations.

Porridge from LR-1 and LR-6 blends was rated similarly in all the attributes and therefore they present an identical profile. LR-4 on the other hand shows a profile which is somewhat comparable to the earlier blends in other attributes but dips in its score for aroma, which changes its outline. Appearance, colour and taste in all the blends, generally retained a score of about 7 , and consistency and mouth-feel, 7.5 or greater. These scores interpret as "like moderately" and "like very much" on the 9-point hedonic scale. For these sets of attributes, no significant differences $(p>0.05)$ were recorded among the three blends. In the case of aroma, however, the blends were markedly different $(p<0.05)$, with LR-4 being rated the lowest among the three.

Out of the sixty caregivers who were interviewed, $91.8 \%$ were willing to buy both LR-6 and LR-1 whereas $83.6 \%$ were willing to buy LR-4. Chi squared test (Table 4) indicated no significant differences $(p>0.05)$ among these responses.

Table 4. Product acceptability, comments and willingness-to-buy.

\begin{tabular}{llllll}
\hline \multirow{2}{*}{ Product } & \multirow{2}{*}{ Acceptability } & Inference & \multicolumn{4}{l}{ Willingness to Buy } \\
\cline { 3 - 5 } & & & Frequency & $\chi^{2}$ & p-value \\
\hline LR-1 & $7.9 \pm 1.3^{\text {a }}$ & Very much & 56 & & \\
LR-4 & $7.6 \pm 1.3^{\text {a }}$ & Very much & 51 & 2.807 & 0.246 \\
LR-6 & $8.0 \pm 1.2^{\text {a }}$ & Very much & 56 & & \\
\hline
\end{tabular}

\subsection{Proximate Composition, Mineral and Vitamin Content of the Three Preferred Complementary Food Formulations}

Proximate composition, beta-carotene levels and mineral content of the three preferred complementary foods are shown in Table 5. Considerable differences $(p<0.05)$ were observed between the 3 formulae for all the nutrients apart from ash. Moisture content ranged between $6.7-9.7 \%$ for the flour blends.

LR-1 had a significantly high content of calcium. LR-4 was significantly high in energy, protein, fat, iron and betacarotene, whilst LR-6 had the highest carbohydrate and zinc. LR-1 had negligible amounts of beta-carotene. LR-6, which contained the same quantity of mango, recorded a small amount of beta-carotene content. LR-4 provides a much higher nutrient profile than the other two formulae.

Table 5. Proximate Composition, Mineral and Vitamin content of the 3 preferred complementary food formulations.

\begin{tabular}{lllll}
\hline Nutrient Composition & LR-1 & LR-4 & LR-6 & EAR (7-12 mo* \\
\hline Energy (Kcal/100g) & $393.99 \pm 0.89^{\mathrm{b}}$ & $427.77 \pm 0.11^{\mathrm{c}}$ & $383.80 \pm 0.16^{\mathrm{a}}$ & $400 \mathrm{kcal}$ \\
Moisture (\%) & $9.34 \pm 0.01^{\mathrm{b}}$ & $6.70 \pm 0.01^{\mathrm{a}}$ & $9.70 \pm 0.00^{\mathrm{c}}$ & $3-8 \%$ \\
Protein $(\mathrm{g} / 100 \mathrm{~g})$ & $14.83 \pm 0.12^{\mathrm{a}}$ & $15.82 \pm 0.17^{\mathrm{b}}$ & $15.52 \pm 0.08^{\mathrm{b}}$ & $9.6 \mathrm{~g}$ \\
Fat $(\mathrm{g} / 100 \mathrm{~g})$ & $7.50 \pm 0.16^{\mathrm{a}}$ & $12.20 \pm 0.78^{\mathrm{b}}$ & $5.80 \pm 0.05^{\mathrm{a}}$ & $30 \mathrm{~g} / \mathrm{d}$ \\
Ash $(\mathrm{g} / 100 \mathrm{~g})$ & $1.50 \pm 0.04^{\mathrm{a}}$ & $1.65 \pm 0.06^{\mathrm{a}}$ & $1.52 \pm 0.02^{\mathrm{a}}$ & $<3 \%$ \\
Carbohydrate $(\mathrm{g} / 100 \mathrm{~g})$ & $66.87 \pm 0.26^{\mathrm{b}}$ & $63.63 \pm 0.31^{\mathrm{a}}$ & $67.46 \pm 0.15^{\mathrm{b}}$ & $95 \mathrm{~g} / \mathrm{d}$ \\
Iron $(\mathrm{mg} / 100 \mathrm{~g})$ & $3.61 \pm 0.40^{\mathrm{a}}$ & $6.65 \pm 0.24^{\mathrm{b}}$ & $4.00 \pm 0.13^{\mathrm{a}}$ & $11.6 \mathrm{mg} / \mathrm{d}$ \\
\hline
\end{tabular}




\begin{tabular}{lllll}
\hline Nutrient Composition & LR-1 & LR-4 & LR-6 & EAR (7-12 mo)* \\
\hline Zinc $(\mathrm{mg} / 100 \mathrm{~g})$ & $0.90 \pm 0.01^{\mathrm{a}}$ & $1.83 \pm 0.13^{\mathrm{b}}$ & $3.44 \pm 0.10^{\mathrm{c}}$ & $6.9 \mathrm{mg} / \mathrm{d}$ \\
Calcium $(\mathrm{mg} / 100 \mathrm{~g})$ & $31.26 \pm 2.21^{\mathrm{b}}$ & $22.94 \pm 0.01^{\mathrm{a}}$ & $23.33 \pm 0.01^{\mathrm{a}}$ & $417 \mathrm{mg} / \mathrm{d}$ \\
Vitamin C $(\mathrm{mg} / 100 \mathrm{~g})$ & $1.12 \pm 0.00^{\mathrm{b}}$ & $1.12 \pm 0.00^{\mathrm{b}}$ & $0.90 \pm 0.01^{\mathrm{a}}$ & $25 \mathrm{mg} / \mathrm{d}$ \\
$\beta$-carotene $(\mu \mathrm{g} / 100 \mathrm{~g})$ & $\mathrm{NS}^{\dagger}$ & $5106.7^{\mathrm{b}}$ & $334.0^{\mathrm{a}}$ & - \\
RE $(\mu \mathrm{g} / 100 \mathrm{~g})$ & $\mathrm{NS}$ & $851.12^{\mathrm{b}}$ & $55.67^{\mathrm{a}}$ & $400 \mu \mathrm{g} / \mathrm{d}$ \\
\hline
\end{tabular}

Values are means of triplicate determination \pm standard deviation. Means within a row with different superscripts are significantly different $(\mathrm{p}<0.05)$. ${ }^{\dagger}$ Not significant. * EAR- Estimated Average Requirements [17].

\section{Discussion}

This research aimed at using locally available food ingredients rich in micronutrients, in formulating complementary food for infants' 6-12 mo of age. This would contribute to solving both protein energy malnutrition and micronutrient deficiencies (especially iron and vitamin A deficiencies) among infants in developing countries. In this study local rice, soybean, cowpea, groundnuts, palm oil, mango and egg yolk were used to formulate weaning porridge.

Sensory evaluation showed that blends containing mango were the best in terms of colour, aroma and taste. Appearance, which includes colour, is a primary attribute which attracts consumer attention and therefore influences acceptance and purchase of food products [20]. Appearance of porridge from all six complementary food formulae was either liked very much or liked extremely. Scores for colour, on the other hand were significantly different $(p<0.05)$ and ranged between 5.1 and 8.6, the least rating corresponding to LR-2 and LR-3. LR-6 and LR-4 were rated higher for their colour compared to LR-5 and LR-1. The high rating for LR-6 could be due to addition of mango which gave the porridge a creamy yellowish colour as such was pleasant and attractive to panelist.

Aroma of porridge prepared from the blends must have been influenced by either cowpea or groundnuts. LR-5 and LR-3, which contained cowpea, received the lowest rating, perhaps as a result of the beany flavor which was more intense in the cowpea. Cowpea is known for its beany flavor which is usually not acceptable by some consumers [21]. As a result, aroma was a limiting sensory attribute for these two weaning formulae (Table 3). Aroma may lead to the rejection of complementary food by infants if it turns out to be unattractive. Acceptance of food by infants has been shown to correlate with its taste, with sweetness being the most preferred $[22,23]$. Taste of porridge from the 6 initial blends ranged from "dislike slightly" to "like very much" and was in the order LR-6, LR-4, LR-1>LR-2>LR-3>LR5. Although some similarities in taste occurred among some porridge samples, considerable differences $(\mathrm{p}<0.05)$ generally existed among the samples. Apart from LR-3 (which also contained cowpea), porridge from blends containing mango flour (LR-1 and LR-6) showed promising taste and were both liked very much by panelists.

Consistency and mouth-feel are considered important in semi-solid foods. In complementary foods, this may influence the extent of consumption, since children of this age may only swallow and not be able to chew on particles. This attribute directly influences preference among children [24], and semi-liquid porridge is the most appropriate. Rating for these two attributes were within the acceptable range, since all the blends received a score of 6 (like slightly) or higher. None of the products were significantly different $(p>0.05)$ in terms of consistency and mouth-feel, an indication that none of the ingredients adversely affected these attributes.

Acceptability (Table 3 ) ranged from 6.3 (like slightly) to 8.6 (like extremely) for porridge made from the 6 complementary food formulae. Even though preference for the products differed markedly $(p<0.05)$, some similarities in acceptability among LR-6, LR-4 and LR-1 were observed. LR-3 and LR-5, which contained cowpea, had low acceptability scores because of the undesirable beany flavor which impacted on their aroma and taste. LR-6, LR-4 and LR-1 had no limiting sensory characteristics and were widely acceptable to the trained panel.

\subsection{Consumer Acceptability}

Overall acceptability for the three selected blends ranged between 7.6 and 8.2 for LR-4 and LR-6 respectively (Table 4). This range of acceptability rating translates into "like very much" on the 9-point hedonic scale. In general, the formulations with soybeans and mango flour with or without groundnut (LR-1 and LR-6) were scored a little higher than the formulation with soybean, palm oil and egg (LR-4). The low score for LR-4 may be attributed to the inclusion of palm oil and egg yolk in this blend which must have resulted in an aroma not quite familiar to the panelists. Regardless of the varying ratings, no significant difference $(\mathrm{p}>0.05)$ was established for acceptability among porridge from the 3 weaning formulae, an indication that all three were liked to a similar extent. Mangoes have a sweet taste and pleasant aroma. This may account for the high acceptability for the mango based products.

\subsection{Nutrient Composition of the Complementary Foods}

Energy, protein and micronutrients such as iron, zinc, calcium, vitamin $\mathrm{A}$ and $\mathrm{C}$ are important for optimal growth, and development of infants and young children [25]. It is recommended that infant food should be well balanced to meet about $50 \%$ of the reference nutrient intake [26]. Considerable differences $(p<0.05)$ were observed between the three selected formulae for all the nutrients except ash. LR-4 had the highest amount of energy, protein, fat, betacarotene and iron but was lowest in carbohydrates. This is 
attributed to the palm oil and egg yolk in this formulation, which are both rich in fat and beta-carotene. Red palm oil is rich in beta-carotene which is a remarkable source of vitamin A [13]. It is also culturally acceptable and used in the preparation of various traditional foods. This helps prevent vitamin A deficiency among children as well as provide antioxidants which acts as a buffer against free radicals to prevent cardiovascular diseases [27, 28, 29, 30]. Several feeding trials incorporating red palm oil into diets at household level or into commercially manufactured products has shown improvement in beta-carotene content of food [11, $12,13]$. Consumption of red palm oil incorporated in a sweet snack or biscuits significantly improved plasma retinol concentrations in children with subclinical vitamin A deficiency [14]. Palm oil retains about $80 \%$ of its carotenoids after processing, and therefore makes a remarkable source of Vitamin A. In this study, LR-4 (which contained 5\% of palmoil) significantly improved the beta-carotene content of the formula above its EAR compared to the formulae without palm oil. Palm oil could therefore be used as a great potential to address the problem of vitamin A deficiency.

LR-4 was rich in proteins and iron. The high content of protein and iron in LR-4 could be due to egg yolk in the formulation. Egg yolk is a rich source of protein, amino acids and iron [9]. It is also one of the few naturally containing vitamin D [10]. The inclusion of these ingredients (palm oil and egg yolk) at 5\% contributed to enhancing the protein, iron and vitamin A content of the weaning food. WHO recommends the inclusion of vegetable oil in infant formulae to serve as a carrier for fat soluble vitamins and also increase energy density [31].

LR-4 contained 5\% less rice flour than the other formulae and this accounted for its significantly lower $(p<0.05)$ carbohydrate content. LR-1 had the highest content of calcium but had the lowest level of most of the nutrients. This blend contained insignificant amounts of $\beta$-carotene and retinol LR-6 generally had a nutritional composition that lay between that of LR1 and LR4. Nevertheless, its fat, carbohydrate and iron contents were comparable to those of LR-1. The relatively lower amounts of beta carotene and retinol in these two formulae (LR1 and LR-6) compared to LR- 4 could be attributed to low amount of mango in these blends. Analysis of different types of mangoes showed a progressive increase in beta-carotene levels as fruit ripens [8]. Studies have also shown a higher serum retinol and betacarotene levels after consumption of mangoes by children in Senegal [7]. Ripe mangoes are rich in beta-carotene and may help improve vitamin A status [32,33].

The formulations offered appreciable amounts of macronutrients which satisfied at least half of their EARs. In the case of the micronutrients, however, only LR-4 and LR-6 contained enough zinc to meet more than half its EAR. Iron and vitamin $\mathrm{C}$ were generally lower in the weaning food blends, compared with their EARs. The $\beta$-carotene and retinol content presented by LR-4 exceed the EAR for these nutrients whereas LR-6 met about one-tenth of retinol and less than half of $\beta$-carotene.
Moisture content of the formulated complementary food flour ranged between $6.7-9.7 \%$. This low moisture contents which implies low water activity will help maintain keeping qualities during storage [34]. High moisture levels are conducive for the growth of micro-organisms and also facilitate chemical reactions which cause deterioration in product quality [34]. Moisture is a critical factor since weaning formulae are usually prepared in large quantities and stored for use as an when it is needed.

\section{Conclusion}

The study has shown that food commodities such as rice, soybean, eggs, palm oil, and mangoes normally used as staples for adult have the potential being used as complementary food to improve both beta-carotene and iron contents for children. The sensory evaluation and acceptability studies conducted indicated that three different formulations, namely LR-1, LR-4 and LR-6 were widely acceptable. Nutrient content of these three blends were appreciable, particularly LR-4, whose energy, protein, fat, as well as vitamin A, iron content met more than half of the EAR. These complementary formulae may be a potential source of micronutrient that can help solve both macro and micro-nutrient malnutrition (especially vitamin A and iron) in Ghana and the developing world. The additional lesson from this study is that local ingredients should not be underestimated because they have the potential of addressing the problem of infant micronutrient deficiencies in the developing world.

\section{Acknowledgment}

This project was sponsored by the Canadian funded AfricaRice project with the theme: "Enhancing Food Security in Africa through the Improvement of Rice PostHarvest Handling, Marketing and the Development of New Rice-Based Products."

\section{References}

[1] Low JW, Arimond M, Osman N, Cunguara B, Zano F, Tschirley D (2007). A food-based approach introducing orange-fleshed sweet potatoes increased Vitamin A intake and serum retinol concentrations in young children in rural Mozambique. J. Nutr. 137: 1320-1327.

[2] Tontisirin K, Nantel G, Bhattacharjee L (2002). Food -based strategies to meet the challenges of micronutrient malnutrition in the developing world. Proceedings of the Nutrition Society 61: 243-250.

[3] Johns $\mathrm{T}$ and Sthapit BR (2004). Biocultural diversity in the sustainability of developing-country foods systems. Food and Nutrition Bulletin 25:143-155.

[4] Johns T (2003). Plant biodiversity and malnutrition: Simple solutions to complex problems. African Journal of Food, Agriculture, Nutrition and Development 3(1): 45-52. 
[5] Mahmoud AH and El Anany AM (2014). Nutritional and sensory evaluation of a complementary food formulated from rice, faba beans, sweet potato flour and peanut oil. Food Nutr Bull. 35(4):403-13.

[6] Amissah JGN, Ellis WO, Oduro I, Manful JT (2003). Nutrient composition of bran from new rice varieties under study in Ghana. Food Control. 14 (1): 21-24.

[7] Carlier C, Etchepare M, Ceccon JF, Mourey M, AmedeeManesme O (1992). Efficacy of massive oral doses of retinyl palmitate and mango (Mangifera indica L.) consumption to correct an existing vitamin A deficiency in Senegalese children. Br J Nutr. 68(2): 529-40.

[8] Litz ER (2009). The Mango Botany, Production and Uses. $2^{\text {nd }}$ edtion. MPG Book Group Bodmin, pp 488.

[9] Nimalaratne C, Wu J, Schieber A. (2013). Egg Yolk Carotenoids: Composition, Analysis, and Effects of Processing on their Stability: In Carotenoid Cleavage Products 18: 219-225.

[10] Mattila PH. (2015). Enrichment of hen eggs with vitamin D for human health:In Watson RR and De Meester (ed). Handbook of eggs in human function 9:167-180.

[11] Kamaruzaman N, Babji, AS, Ismail WRW, Peng FS (2015). Vitamin E Contents and Oxidative Stability of Red Palm Oils Blended Chicken Nuggets during Frozen Storage. Malaysian Journal of Analytical Sciences, 19(1): 202-212.

[12] Mba OI, Dumont M J, Ngadi M (2015). Palm oil: Processing, characterization and utilization in the food industry-A review. Food Bioscience 10: 26-41.

[13] Zhu C, Cai Y, Gertz E, Lafrano M, Burnett D, Burri B (2015). Red palm oil-supplemented and biofortified gari on the carotenoid and retinyl palmitate concentrations of triacylglycerol-rich plasma of women. Nutr Res. earch 35(11):965-974.

[14] Benade AJ (2003). A place for palm fruit oil to eliminate vitamin A deficiency. Asia Pac J Clin Nutr 12 (3): 369-72.

[15] Mitcham B (2010). Mango Handling and Ripening Protocol, Dept of Plant Science, University of Califorina, Davis.

[16] USAID Peanut Collaborative Research support Program (CRSP) and IUFoST (2012). Processing for Aflatoxin Elimination in Peanut Products (Reduction below Regulation Thresholds). Training Workshop Manual. CSIR-Food Research Institute.

[17] WHO and FAO (2006). "Estimated Average Requirement (calculated values) based on FAO/WHO Recommended Nutrient Intakes." FAO/WHO Guidelines on Food Fortification with Micronutrients.

[18] AOAC (2000). Official Methods of Analysis. Association of Official Analytical Chemists, Washington, DC.

[19] Novotny JA, Gebauer SK, Baer DJ (2012). Discrepancy between the Atwater factor predicted and empirically measured energy values of almonds in human diets. Am J Clin Nutr. 96:296-301.
[20] Imram $N$ (1999). The role of visual cues in consumer perception and acceptance of a food product. Nutrition and Food Science 99:224-228.

[21] Nimoh F, Asuming-Brempong S, Sarpong DB (2012)."Consumer Preference for Processed Cowpea Products in Selected Communities of the Coastal Regions of Ghana", Asian Journal of Agriculture and Rural Development 2(2): 113-119.

[22] Drewnowski A, Mennella JA, Johnson SL, Bellisle F (2012). Sweetness and Food Preference. J. Nutr. 142: 1142S-1148S.

[23] Mennella JA, Bobowski N K, Reed DR (2016). The development of sweet taste: from biology to hedonics. Rev Endocr Metab Disord 17(2): 171-8.

[24] Parker ME, Schroeder DG, Begin F, Hurtado E (1998). Maternal preferences for consistency of complementary foods in Guatamala. Food Nutr. Bull 19:6-12.

[25] Huffman SL and Martin LH (1994). First Feedings: Optimal Feeding of Infants and Toddlers. Nutr. Res.14: 127-59.

[26] Zand N, Chowdhry BZ, Pollard LV, Pullen FS, Snowden MJ, Zotor FB (2015). Commercial 'ready-to-feed'infant foods in the UK: macro-nutrient content and composition. Maternal \& child nutrition 11(2); 202-214.

[27] Heber D (2000). Colourful cancer prevention: $\alpha$-carotene, lycopene and lung cancer. Am J Clin Nutr. 72 (4): 901-2.

[28] Arnao MB, Canoa A, Acosta M (2001). The hydrophilic and lipophilic contribution of total antioxidant activity. Food Chemistry 73:239-244.

[29] Tapiero H, Townsend DM, Tew KD (2004). The role of carotenoids in the prevention of human pathologies. Biomedicine and Pharmacotherapy 58(2):100-110.

[30] Imoisi OB, IIori GE, Agho I, Ekhator JO (2015). Palm oil, its nutritional and health implications (Review). J. Appl. Sci. Environ. Manage. 19(1):127 - 133.

[31] FAO/WHO (1998). Preparation and use of Food-based guidelines. Report of a joint FAO/WHO Consultation. WHO technical Report series 880, WHO-Geneva.

[32] Hiraganahalli B, Chinampudur V, Dethe S, Mundkinajeddu D, Pandre M, Balachandran J, Agarwal A (2012). Hepatoprotective and Antioxidant Activity of Standardized Herbal Extracts. Pharmacogn Mag. 8(30): 116-23.

[33] Pobee RA, Johnson PNT, Akonor PT, Buckman SE (2017). Nutritional, Pasting and Sensory Properties of a weaning food from Rice (Oryza Sativa), Soybeans (Glycine max) and Kent Mango (Mangifera Indica) flour blends. Afr. J. Food Agric. Nutr. Dev. 17(1):11533-11551.

[34] Chirife J, Zamora MC, Motto A (2006). The correlation between water activity and $\%$ moisture in honey: fundamental aspects and application to Argentine honeys. J. Food Engineering 72(3): $287-292$. 